\title{
LA CONSTRUCCIÓN IDENTITARIA EN LA POESÍA DE JUANA CASTRO. COMPROMISO E INDAGACIÓN, CLAVES PARA UNA EDUCACIÓN LITERARIA
}

\author{
María Remedios Sánchez García. Raquel Lanseros Sánchez \\ Universidad de Granada. Universidad de León.
}

\section{RESUMEN}

La obra poética de Juana Castro está vertebrada por una serie de elementos que la dotan de singularidad en el panorama de la poesía española contemporánea: su admiración por la naturaleza (en especial por el paisaje de su comarca natal de Los Pedroches), su fuerte compromiso con la conciencia de la identidad femenina y su preocupación constante por el mundo de la pedagogía y la educación, así como por la transmisión de la poesía en el aula desde edades tempranas. Poeta de vocación personal e independiente, su obra ha sido construida al margen de modas o tendencias estéticas externas, primando siempre en su escritura la diversidad de influencias y estilos. Tradicional y a la vez vanguardista, la poesía de Juana Castro indaga en la búsqueda de la libertad individual, la lucha contra la alienación y la construcción identitaria desde el punto de vista de la mujer; siendo una de sus principales prioridades intelectuales la experimentación y fijación en el imaginario filosófico y estético de la corporeidad femenina. El presente artículo dialoga con su profundización poética en la esencia del aliento femenino y su inclinación vocacional hacia una educación literariatrascendida y alejada de simplificaciones.

Palabras Clave: Juana Castro, poesía, educación literaria, poesía de la diferencia, poetas españolas.

\begin{abstract}
The poetic work of Juana Castro is backed by a series of elements that give it singularity in the panorama of contemporary Spanish poetry: her admiration for nature (especially for the landscape of her native region of Los Pedroches), her strong commitment with the awareness of the feminine identity and her constant concern for the world of pedagogy and education, as well as for the transmission of poetry in the classroom from early ages. Poet of personal and independent vocation, her work has been built outside external fashions or aesthetic tendencies, always emphasizing in her writing the diversity
\end{abstract}

Recibido: 24-01-2017 / Aceptado: 20-07-2017 
of influences and styles. Traditional and at the same time avant-garde, Juana Castro's poetry explores the search for individual freedom, the struggle against alienation and the construction of identity from the point of view of women; being one of her main intellectual priorities the experimentation of the feminine corporeity and its attachment to the philosophical and aesthetic imaginary. The present article dialogues with her poetic deepening in the essence of the feminine breath and her vocational inclination towards a literary education which is transcended and far from simplifications.

KEY WoRDS: Juana Castro, poetry, literary education, poetry of difference, Spanish poets.

\section{Introducción. Datos biográficos E inicios poéticos}

Juana Castro nació en Villanueva del Duque (Córdoba), en la comarca de Los Pedroches, el 20 de febrero de 1945. Es importante señalar su lugar natal, porque tiene mucha trascendencia temática a lo largo de toda su obra. Ella misma lo subraya de este modo:

Dicen que somos lo que éramos a los nueve años. Ese paisaje y esa forma de vida me marcó, fue un conflicto generador, el otro era el mundo de las mujeres, el cuerpo. Una comarca aislada, con caminos tercermundistas, te hace conocer y vivir la soledad, el extrañamiento. No hay otra manera que poner a trabajar tus talentos. El mío era la palabra. Pero no fui lo suficientemente valiente, como sí lo soñaba en la adolescencia: dediqué a escribir apenas una pequeña porción de tiempo ${ }^{1}$.

También Criado Costa se hace eco de este pesar que experimenta Juana por no haber empezado a publicar más pronto:

Desde muy temprano siente la emoción poética, el encanto de la palabra y en definitiva el gusto por la poesía, que le llevará a la necesidad íntima del mágico sueño de «ensartar una a una las perlas de la noche en tu pobre bolígrafo», como dice la propia autora. Por esto, quizá, le parecen demasiados los años transcurridos hasta que se decida a publicar su primer libro: Cóncava mujer, en 1978. No serían años en balde, sino días y horas almacenando vivencias, nostalgias como heridas, tardes de encinas y soledades que felizmente se fueron confabulando en sus libros de poemas ${ }^{2}$.

Parece evidente que la vocación poética de Juana fue muy temprana y muy punzante, aunque los vaivenes y peripecias de la vida retrasaran su debut poético más de lo que su fuerte sentimiento de amor por los versos hubiera deseado. Esto responde ella cuando le preguntamos precisamente por esos inicios poéticos que tuvieron lugar ya rebasados los treinta años:

En mi tiempo, y antes también, en la generación del 50, las mujeres no publicábamos a los veinte, publicábamos en la treintena. Llevábamos el trabajo de dentro y el de

\footnotetext{
${ }^{1}$ Entrevista personal a Juana Castro, realizada en Córdoba a 26 de febrero de 2016. Contenida en Los poetas toman la palabra. La construcción de la educación literaria en los autores nacidos en posguerra, Madrid, Visor Libros, 2017.

${ }^{2}$ Criado Costa, J., «Evolución poética de Juana Castro», en Boletín del Instituto de Estudios Giennenses, 153, 1 (1994), pp. 159.
} 
fuera, la triple jornada, los hijos... Yo nací en el cuarenta y cinco, pertenecería a la generación de los novísimos, pero mis intereses y mi tiempo, mis lecturas eran otras, aunque cuando los leí pude compartir su estética, por ejemplo con Antonio Colinas o con Pere Gimferrer. Ubicarme... en los primeros tiempos en un neobarroquismo. A partir del 2000 en el neorruralismo, pero a la vez en la poesía que se llamó de la diferencia, fundamentalmente por primar sobre todo la diversidad de intereses y estilos ${ }^{3}$.

\section{Juana Castro, una poeta fuera de generación. Poesía de la experiencia versus poesía} DE LA DIFERENCIA

No es fácil ubicar generacionalmente a una poeta como Juana Castro, porque su creación ha sido siempre independiente, alejada de escuelas, grupos o capillas. Tiene razón cuando afirma que cronológicamente pertenecería al grupo de los novísimos, al menos en cuanto a su fecha de nacimiento se refiere. Sin embargo, cuando apareció publicado su primer libro, Cóncava mujer, en 1978, la renombrada antología de José María Castellet ya tenía ocho años y para entonces nuevos modos de hacer poesía completamente diferentes a los novísimos ya se estaban gestando. Tengamos en cuenta que hacia finales de los años setenta la estética novísima se encontraba ya en franca decadencia -sobre todo sus corrientes más acendradas en el barroquismo o el venecianismo-, y se fueron abriendo paso otros poetas de similar edad cuyas voces habían sido ahogadas en el fragor del boom novísimo. Hablamos de plumas que intentaron llevar la poesía hacia una nueva rehumanización, como Miguel D’Ors, Juan Luis Panero o Eloy Sánchez Rosillo, tal y como ha escrito José Enrique Martínez en un artículo en el que constata «el dualismo y la manera de concebir y practicar la poesía» en este tiempo ${ }^{4}$.

Juana Castro, por fecha de nacimiento y de publicación de su primer libro, figura entre esas voces nacidas en la década de los cuarenta que comenzaron a despuntar a inicios de los ochenta, ajenas a la suntuosidad esteticista de los novísimos, pero también a la incipiente corriente que derivó posteriormente en llamarse 'poesía de la experiencia' o 'poesía figurativa's. Como ella misma afirmaba en la cita de su entrevista personal transcrita más arriba, su ubicación podría hallarse, a grandes rasgos, en la llamada 'poesía de la diferencia'. Conviene recordar, para ubicarnos en términos históricoliterarios, en qué consistía esta y cuáles fueron los motivos del enfrentamiento que ambas corrientes ('poesía de la experiencia' y 'poesía de la diferencia') protagonizaron

\footnotetext{
${ }^{3}$ Entrevista personal a Juana Castro, realizada en Córdoba a 26 de febrero de 2016. Contenida en Los poetas toman la palabra [...], ob. cit. s/p.

${ }^{4}$ Martínez, J. E., «Experiencia y experimentación (res/verba) en la poesía española última», en Estudios humanísticos. Filología, 20 (1998), p. 222.
}

${ }^{5}$ García Martín, J. L., La generación de los ochenta, Valencia, Mestral, 1980. 
durante las dos últimas décadas del siglo xx.

Existe una dicotomía forma / contenido a la hora de abordar el hecho poético, que ha propiciado que surjan visiones diferentes sobre la esencia misma de la poesía. Estas visiones han estado enfrentadas en muchos momentos históricos, como se puede observar en choque de estilos del mester de juglaría y el mester de clerecía, el conceptismo y el culteranismo o, más recientemente la poesía de la experiencia y la poesía de la diferencia. En todos estos casos, los seguidores de una u otra estética, han tratado de propugnar sus propias tesis poéticas por encima de las otras, a la vez que intentaban crear un canon ajustado a los autores de su misma corriente. Remedios Sánchez García trata este fenómeno en El canon abierto:

Partiendo de esto, de que hay un canon que eligen para perdurar los teóricos estudiosos de los vencedores, si lo planteamos desde un enfoque puramente epistemológico, ¿quiénes son las personas, esos sabios, que determinan lo que debe conformar o no el canon? ¿Quién marca lo que no debe perderse, lo que hay que preservar contra viento y marea? Y, ¿atendiendo a qué criterios se ha venido haciendo ${ }^{6}$

Sánchez García remite a los hechos cuando, en relación con lo anterior, añade que, «si de verdad se pretende preservar y mantener lo mejor de cada momento hay que ser consciente de que conviene sobrevolar como críticos la ideología hegemónica porque, por ejemplo, Góngora, uno de los pilares barrocos, ha sido un autor ignorado por el canon durante tres siglos hasta que los poetas de la Generación del 27 lo recuperan con el archiconocido acto de Sevilla» ${ }^{7}$.

En palabras de Gabriel Núñez Ruiz, se entiende el canon como «un complejo proceso histórico en el que intervienen factores de diversa índole que han contribuido a lo largo del tiempo tanto a configurarlo como a modificarlo y que tienen que ver con la Estética, con la constitución de las disciplinas, con la organización del currículum, y por tanto, con el papel que juegan la literatura y las humanidades en las sociedades modernas» ${ }^{8}$.

Una de las claves de este asunto es el enfoque y la disposición hacia la tradición poética, pudiendo decantarse de modo general por abrazarla, o bien por intentar superarla, desde una vía más rupturista. En todas las generaciones se dan ambas posturas, e incluso, a veces, en una misma persona, puesto que se trata de dos tendencias lógicas en la evolución del conocimiento humano. Para Luis Antonio de Villena, por

\footnotetext{
${ }^{6}$ Sánchez García, R., El canon abierto (Última poesía en español), Madrid, Visor, 2015, p. 10.

${ }^{7}$ Sánchez García, R., El canon abierto[...], ob. cit., p.11.

${ }^{8}$ Núñez Ruiz, G., Lectura literaria y lecturas del mundo: Notas sobre la lectura y la educación literaria. Almería, Universidad de Almería. Red de Universidades Lectoras, 2014, p.65.
} 
ejemplo, los novísimos, generación a la que él pertenece -aunque figurase entre sus integrantes tardíos-, «fue rupturista porque rechazaba lo inmediatamente anterior (la generación del 50, quizá con la excepción amistosa de Gil de Biedma, quedaba en una curiosa zona de sombra, en un extraño sí es-no es) y porque la estética que preconizaba, aunque acaso no nueva en cada uno de sus ingredientes detalladas, resultaba nueva en aquel momento» 9 .

También es curioso señalar que no siempre lo que los poetas afirman teóricamente se corresponde después con lo que realizan en su poesía. Veamos por ejemplo la postura que preconiza Jaime Gil de Biedma en sus ensayos El pie de la letra, donde defiende que la poesía no es comunicación, algo opuesto a los rasgos característicos de la poesía de la Generación del 50, a la que él está adscrito:

Si la poesía no es comunicación, y tampoco es conocimiento, ¿qué es entonces? Ni lo sé ni estoy demasiado seguro de que interese saberlo; o quizá sí lo sé, cuando no me empeño en definirla. [...] La comunicación es un elemento de la poesía, pero no define la poesía; la actividad poética es una actividad formal, pero nunca es pura y simple voluntad de forma. Hay un cierto grado de comunicación en todo poema; hay una mínima voluntad de forma -una voluntad de orientación del poema- en el poeta surrealista. La poesía es muchas cosas, y un poema puede meramente consistir en una exploración de las posibilidades concretas de las palabras ${ }^{10}$.

Pues bien, con los últimos coletazos de la estética novísima, apareció en Granada una corriente poética que trataba de dar un giro a la poesía, devolviéndola a la intimidad, el tratamiento del yo y la observación de los acontecimientos cotidianos. Se trataba de La Otra Sentimentalidad de la que, al poco, deriva con muchos de sus componentes en la Poesía de la Experiencia. El teórico de este movimiento fue el profesor Juan Carlos Rodríguez, quien enumeraba así a sus integrantes y afines:

Antonio Jiménez Millán, por ejemplo, estuvo integrado desde el principio, pero hubo mucha más gente... [...] El profesor Antonio Sánchez Trigueros y sus aportaciones, poetas de tendencia experiencial como Rafael Juárez, Vicente Sabido o José Gutiérrez, Miguel D’Ors llegó más tarde, José Tito Rojo entre otros. [...] Teresa Gómez y Ángeles Mora aportaban una clave decisiva en la época, es decir, la búsqueda de una normalidad feminista de izquierdas, frente a la llamada 'literatura de mujeres'. Por entonces, la profesora Ángela Olalla iniciaba sus trabajos teóricos sobre el feminismo ${ }^{11}$.

Prieto de Paula define así las principales características de esta corriente estética:

Al fondo, podía percibirse un vacío de expectativas teleológicas y un desmantelamiento filosófico que habían supuesto un territorio yermo en el que

\footnotetext{
${ }_{9}^{9}$ Villena, L. A. de, Postnovísimos, Madrid, Visor, 1986, p. 12.

${ }^{10}$ Gil de Biedma, J., El pie de la letra, Barcelona, Mondadori, 2001, p. 34.

${ }^{11}$ Rodríguez, J. C., Dichos y escritos (Sobre «La otra sentimientalidad» y otros textos fechados de poética), Madrid, Hiperión, 1999, pp. 52-53.
} 
se asentaba, como única y frágil realidad, la vida del sujeto: su experiencialidad. La experiencia del yo ocupaba el lugar que antaño habían ocupado la poesía ensimismada, el culturalismo desbordante, los vanguardismos alejados del lector común, incluso la metapoesía. La centralidad de ese lujo creado iba de la mano de una expresión menos elitista más comunicativa, cuya vocación de transitividad recordaba, cierto que con otro lenguaje poético más exigente y menos instrumental, las propuestas de los autores civiles y sociales del medio siglo, que habían sido barridas por la poética posterior; pero también las de alguna poesía simbolista de comienzos del siglo. El estilo, caracterizado a menudo por el tradicionalismo expresivo y un evidente desvío del experimentalismo, dista mucho del desaliño de anteriores ensayos realistas ${ }^{12}$.

En respuesta a la anteriormente descrita poesía de la experiencia, corriente considerada por la mayoría de los críticos como dominante (García Posada, 1996), aparece otra que se hizo llamar Poesía de la Diferencia. Los poetas que iniciaron el movimiento fueron Antonio Enrique, Ricardo Bellveser, Fernando de Villena, Carlos Clementson, Gregorio Morales o Pedro Rodríguez Pacheco, tal y como ha aclarado Antonio Rodríguez Jiménez ${ }^{13}$. Fue un grupo muy heterogéneo en escritura y formas, en el que primó, como apuntaba Juana Castro, la diversidad de intereses y estilos. En cualquier caso, sus ideas originales fueron expresadas así en el manifiesto de Antonio Enrique, uno de sus iniciadores, como hemos dicho:

El poeta en el siglo xxI, ha de ser una mentalidad trascendida. Trascenderse implica romper los límites impuestos a nuestra conciencia por todas aquellas presiones que conspiran -en el orden social y religioso- contra la libertad original de toda persona, incluido su derecho a la felicidad. La poesía es, y debe seguir siendo, un reducto contra todos los abusos de poder que contaminan, lesionan $\mathrm{u}$ ofenden la sensibilidad estética, tanto individual como colectivamente. Y consiste también, trascenderse, en la certera intuición de que la realidad es, precisamente, aquello que no puede verse. Pero el poeta solo dispone de un arma, que lo hace inmensamente peligroso a cualquier orden jerárquica establecida: es su emoción. La emoción forma parte esencial del misterio de la escritura. Nos emocionamos no sabemos a ciencia cierta de qué ni por qué. Pero solo la emoción hace que el poema sea duradero. De casi otra cosa no tenemos certidumbre, pero de esto sí: los poemas que quedan son los que nos conmueven (conmovieron sobre todo a nuestros antepasados). La emoción, que es tanto más honda y verdadera cuanto más clara se manifiesta. Es la emoción lo que traza puentes de analogía mediante los símbolos más dispares, las metáforas más apasionantes, maneras todas de penetrar en lo invisible. Usamos las palabras de siempre, pero suscitando sensaciones tales que parecen, estas simples palabras coloquiales, creadas desde el comienzo del mudo para amoldarse a la Idea que todo poema encarna, una idea que inicialmente sobreviene en forma de música y se expande en una estructura silábica o estrófica, esto es, idea en el

\footnotetext{
${ }^{12}$ Prieto de Paula, Á. L., «Entre la disidencia y la asimilación: la poética de la experiencia», disponible en: http://www.cervantesvirtual.com/portales/poesia_espanola_contemporanea/historia_disidencia/ [consultado 04-03-2016].

${ }^{13}$ Rodríguez Jiménez, A., «La creación poética en Cuadernos del Sur, emblema literario de estética y compromiso», en Sánchez García, R., Palabra heredada en el tiempo. Tendencias y estéticas en la poesía española contemporánea (1980-2016), Madrid, Akal, 2016, pp. 135-147.
} 
tiempo: número, inseparable de numen, nombre ${ }^{14}$.

Juana Castro ha sido siempre una escritora independiente y, de algún modo, francotiradora, pues ha defendido sus intereses poéticos personales contra viento y marea, haciendo caso omiso a modas o tendencias estéticas o temáticas externas. Tan solo en ocasión de sus comienzos estuvo vinculada a un grupo literario, como explica Joaquín Criado Costa:

Conoce directamente el mundo literario, que de adolescente tanto le había fascinado; de la mano del Grupo Zubia ${ }^{15}$ de poetas cordobeses, al que perteneció desde 1976, comienza su andadura literaria. [...] Abandonará el Grupo Zubia después de siete años, para dedicarse a la solitaria creación poética. Esta labor en soledad no le impide participar en toda clase de actividades culturales que se desenvuelven a su alrededor, fruto del interés que en ella suscita todo lo relacionado con la poesía, con la mujer y con el amor ${ }^{16}$.

Nos encontramos ante una poeta que rehúsa configurase en una sola estética predefinida, antes muy al contrario, bebe de las fuentes de la tradición y la vanguardia con igual fruición, puesto que ambas son conciliables en tanto que conforman el registro temporal sincrónico de los poetas de finales del siglo xx y comienzos del XXI. Ella misma se expresa así con relación a esta disyuntiva:

Sí, sí, la tradición, pero la vanguardia. No podemos seguir repitiendo las formas de antaño, hay que innovar, buscar nuevos caminos, otra expresión, siempre. No puedo decir cómo conciliar ambos, porque depende del tema, de mi situación anímica en el momento de la escritura. Al final, la solución la da la inspiración momentánea, con más o menos suerte. Conexiones neuronales que tienen lugar en las tripas, las entrañas -más que en el cerebro-. Intento que cada poema sea, hacia mí, creación; hacia los demás, tradición, al menos en una milésima parte, la que conecta con lo que de los clásicos sigue vivo en mí (musicalidad, constantes temáticas...). Y si está vivo en mí, deduzco que también en los demás ${ }^{17}$.

En este sentido, Morales Lomas puntualiza lo siguiente:

$\mathrm{Su}$ creación podemos considerarla bastante personal, lejos de capillas $\mathrm{u}$ organizaciones ideológicas precisas, pero siempre ha existido como firme baluarte una reivindicación del papel de la mujer y un tono doliente, autobiográfico y

\footnotetext{
${ }^{14}$ Enrique, A., «Poética» en web personal del escritor Antonio Enrique, 2009. Disponible en: http://www. antonioenrique.com/Poetica\%202009.html [consultado 18-02-2016].

${ }^{15}$ El Grupo Zubia fue un conjunto de poetas cordobeses que se conformó en 1972 y editó en 1973 su primera antología. Sus componentes iniciales fueron Francisco Gálvez, José Luis Amaro, Rafael Madueño, Pedro Luis Zorrilla, Carlos Rivera, Diego Peláez y Pepe Ramírez, entre otros. Posteriormente se incorporaron al grupo de manera temporal Carlos Clementson, Juana Castro, Heliodoro Díaz y Antonio Rodríguez Jiménez.

${ }^{16}$ Criado Costa, J., «Poesía de granito y jara: Juana Castro», Boletín de la Real Academia de Córdoba de Ciencias, Bellas Letras y Nobles Artes, 135 (1998), p. 204.

${ }^{17}$ Entrevista personal a Juana Castro, realizada en Córdoba a 26 de febrero de 2016. Contenida en Los poetas toman la palabra [...], ob. cit. s/p.
} 
elegíaco que en ocasiones anda inmerso en un surrealismo renovado y onírico en el que el cultivo de la forma ofrece una intensa vitalidad creadora, si bien inicialmente se sustenta tanto temática como formalmente en el manierismo y en el barroco ${ }^{18}$.

\section{LA CONCIENCIA DE LA IDENTIDAD FEMENINA}

Es la poesía de Juana Castro vivencial y sensible, reflejo de recuerdos, sensaciones e ideas que la autora atesora y que irán evolucionando con ella, sin abandonarla jamás. Uno de esos intereses es la identidad femenina, su autoafirmación en un entorno no excesivamente proclive a la realización personal de la mujer y la búsqueda del equilibrio en relación al propio cuerpo. La experimentación y fijación en el imaginario filosófico y estético de esa corporeidad femenina es una de las principales preocupaciones intelectuales de la autora. Así lo observa asimismo Francisco Javier Peñas-Bermejo, a quien el análisis de la poesía de Juana Castro le sugiere la siguiente reflexión:

En el discurso poético de Juana Castro se reivindica la vivencia de la mujer por medio de postulados críticos feministas de la diferencia. En sus versos, la mujer exalta su marca sexual y critica la represión de la expresividad femenina en los cánones culturales. Al subvertir los dogmas de algunas tradiciones míticas y religiosas por medio de una voz doble, bitextual, la del discurso oprimido y la del dominante, Castro renueva la originaria naturaleza creadora de la mujer y exige su participación activa en una reconstrucción de la cultura ${ }^{19}$.

En la biografía redactada para su página $w^{2} b^{20}$, la autora afirma que «un día vio en el quiosco de las Tendillas una revista, Vindicación feminista ${ }^{21}$ y así pudo ponerle nombre a algo que había sido, junto a su madre, percepción y sentimiento». Así lo explica en la entrevista personal que nos concedió:

Elfeminismofueprimerosentimientoy convicción,cuandoleíla revista «Vindicación feminista», que encontré en el kiosco de Las Tendillas de Córdoba es cuando le puse nombre, historia y concepto a ese sentir. Sentir que viví a través de mi madre y de otras mujeres del entorno, por una parte negada su identidad por las leyes y por otra admirando yo su gran dignidad, su saber hacer como administradoras, educadoras, transmisoras de saberes, de cuidado, sanación, cocina... Eran mujeres sabias, especializadas en hierbas, huesos, conservas, salazones... Me cansé pronto del feminismo reivindicativo, prefiero el pensamiento de la diferencia, que me da alas y conecta con la época anterior al patriarcado, antes de que las tres religiones monoteístas eliminaran a la Diosa Madre ${ }^{22}$.

\footnotetext{
${ }^{18}$ Morales Lomas, F., Poesía viva. Ensayos sobre poesía española, Málaga, Fundación Unicaja, 2013, p. 259.

${ }^{19}$ Peñas-Bermejo, F. J., «La poesía de Juana Castro: “¿Destino de la luz no fuera el encenderse?” », Salina: revista de lletres, 16 (2002), p. 213.

${ }^{20}$ Página web personal de la autora Juana Castro, disponible en: www.juanacastro.es [consultado 1801-2017].

${ }^{21}$ Vindicación feminista fue una revista fundada en 1976 por Lidia Falcón y Carmen Alcalde para propiciar la información, el debate y la denuncia sobre la situación de la mujer en España. Se editó hasta 1979.

${ }^{22}$ Entrevista personal a Juana Castro, realizada en Córdoba a 26 de febrero de 2016. Contenida en Los 
Este concepto de la Diosa Madre en la poesía de Juana Castro ha sido estudiado en profundidad por José María Balcells:

Se tiene por cierto que en los albores de la Humanidad una mujer era Dios. Los sumerios, por ejemplo, adoraban a ese Ser Supremo femenino, y en su honor entonaron himnos de alabanza, uno de los cuales se conoce como «La exaltación de Inanna». Datable el texto hacia el 2.300 a.C., en él se recoge el nombre de una divinidad remota, de una divinidad a la que a buen seguro ya se rendía culto desde varios miles de años atrás. Inanna fue la denominación que los pueblos establecidos en el espacio geográfico del Irak actual dieron a su Dios primero, y fue también la versión onomástica que tales gentes empleaban para referirse a la Gran Diosa, o Gran Madre ${ }^{23}$.

Balcells ha analizado un poema de Juana Castro, contenido en su libro Narcisia ${ }^{24}$, que se titula precisamente «Inanna»:

La lectura de Narcisia demuestra que Juana Castro apoyó su inspiración en los conocimientos que había adquirido acerca de la Gran Diosa. [...] Juana Castro acude, en suma, a los mundos cristiano y grecolatino para perfilar su recreación de la Gran Diosa, y enriquece aún su obra basándose en los mitos católicos del origen, pues Inanna es una dea que engendra otra dea por amor a sí misma, de modo similar a la creación del Hijo por el Padre Espiritual en el Cristianismo ${ }^{25}$.

Veamos, pues, el poema «Inanna», de Juana Castro:

Como la flor madura del magnolio

era alta y feliz. En el principio

sólo Ella existía. Húmeda y dulce, blanca,

se amaba en la sombría

saliva de las algas,

en los senos vallados de las trufas,

en los pubis suaves de los mirlos.

Dormía en las avenas

sobre lechos de estambres

y sus labios de abeja

entreabrían las vulvas

doradas de los lotos.

Acariciaba toda

la luz de las adelfas

y en los saurios azules

se bebía la savia

gloriosa de la luna.

Se abarcaba en los muslos

fragantes de los cedros

y pulsaba sus poros con el polen

indemne de las larvas.

¡Gloria y loor a Ella,

poetas toman la palabra [...], ob. cit. s/p.

${ }^{23}$ Balcells, J. M., «El mito del origen en la poesía de Juana Castro», Estudios Humanísticos. Filología, 25 (2003), p.176.

${ }^{24}$ Castro, J., Narcisia, Barcelona, Taifa, 1986.

${ }^{25}$ Balcells, J. M., «El mito del origen en la poesía de Juana Castro», art. cit., p.177. 


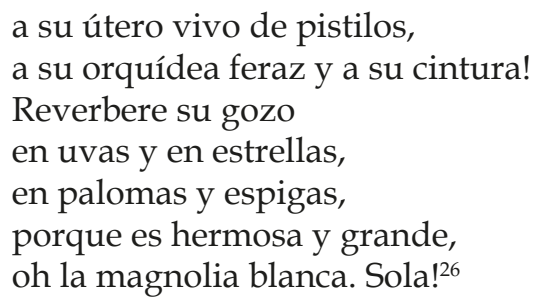

El poema celebra la época primitiva en que solo existía la gran deidad femenina. Es importante notar que la poeta recrea un mundo natural idílico, en que la naturaleza exterior y la naturaleza del cuerpo femenino se entreveran y confunden, como un único símbolo de principio y origen. La elección semántica incluye y sitúa en el mismo plano de significación para describir la realidad, las palabras del orden de la flora y de la botánica, como «flor, magnolio, avenas, lotos, adelfas, savia, cedros, polen, pistilos, orquídea, espigas»; y las palabras que describen la anatomía femenina, como «senos, pubis, vulvas, muslos, poros, útero, cintura». De este modo, la poeta logra crear una atmósfera amable, benigna, apacible, que nos sumerge a la perfección en el mundo paradisíaco pagano, en el que el aliento femenino se glorificaba y respetaba como el orden natural de las cosas.

Abundando en este sentido, Margaret Persin ${ }^{27}$ cita a Sharon Keefe Ugalde, quien en su estudio introductorio a su Sujeto femenino y palabra poética: Estudios críticos de la poesía de Juana Castro, ve la trayectoria de esta poeta cordobesa de la manera siguiente:

El punto de partida es la realidad histórica de la subyugación de las mujeres. De ahí el círculo se abre hacia el imaginario, un mundo de pasión, de placer, de violencia, dolor, divinidad y de amor, y se cierra retornando a la realidad, donde coexiste con el desarraigo inicial una lucidez adquirida en el viaje poético que propone un diálogo, en palabras de Rosario Castellanos, sobre «otra manera de ser $»^{28}$.

Añade Margaret Persin, a propósito de la ciudadanía femenina y del concepto de resistencia en la obra de Juana Castro:

Juana Castro opta por considerar la ciudadanía femenina desde otra perspectiva más amplia y más universal, al contemplar una situación o contexto del pasado que tiene resonancias para el presente. En el caso de Arte de cetrería ${ }^{29}$, por ejemplo, la poeta considera los referentes cambiantes del «tú» y del «yo» en el mundo de la caza con aves para revelar primero cómo el patriarcado domina a la mujer y, segundo, cómo la mujer contemporánea puede encontrar una identidad y una

\footnotetext{
${ }^{26} \mathrm{Al}$ igual que el profesor Balcells, reproducimos el texto español de Narcisia que figura en Castro J., Memoria della luce, Bari, Levante Editori, 1996, p.210.

${ }^{27}$ Persin, M., «Mujer y ciudadanía: los casos de Concha Zardoya y Juana Castro», Lectora: revista de dones i textualitat, 15 (2009. Número dedicado a: Mujeres y naciones), p. 129.

${ }^{28}$ Ugalde, S. K., «Introducción: La aventura del sujeto lírico femenino en la poesía de Juana Castro», en Sharon Keefe Ugalde (ed.), Sujeto femenino y palabra poética: Estudios críticos de la poesía de Juana Castro, Córdoba, Diputación de Córdoba, 2002, p. 13.

${ }^{29}$ Castro, J., Arte de cetrería, Huelva, Diputación de Huelva, 1989.
} 
forma de escape por medio de la palabra, esa otra «forma de ser» ya señalada. En este poemario, la voz poética pone en práctica formas de resistencia al statuquo frente a las estrategias opresivas del patriarcado, utilizando el ave y su dominio en manos de su domador por medio de las trampas y técnicas de la cetrería ${ }^{30}$.

Veamos ahora, a la luz de esta exégesis, uno de los poemas pertenecientes al libro Arte de cetrería, cuyo título es «Cómo se saca al niego de la muda» ${ }^{31}$. La poeta reivindica su derecho a volar como un suceso inevitable, intrínseco a su condición de ser humano. La libertad de la mujer se convierte a sus ojos en un bastión incuestionable, leitmotiv de vida y horizonte perpetuo.

Cuando sueltes los grillos que me atan

y descubras mis ojos para el aire,

tal vez haya ya el vuelo

perdido su placer en la costumbre.

A un idilio tan frío

sólo puede la muerte.

Efectivamente, y como constata Porro Herrera:

Sus múltiples lecturas le sirvieron de modelo para la comprensión elaborada de lo que desde hacía mucho tiempo ella había vislumbrado y hecho suyo: la afirmación de la mujer desde su mismidad. Feminismo como compromiso, como opción de vida, sentido de manera visceral con la clara intención de dejar sentado de una vez el sentido trágico de la condición humana en general, de la clase mujer en particular y de la conflictiva relación intersexos, el descubrimiento de una identidad tan dolorosa como afirmativa y radiante en sus primeros libros para abordarla no con menos dolor, pero sí con más sosiego en el último: Los cuerpos oscuros» ${ }^{32}$.

\section{Juana castro, maestra. Influencia de la pedagogía y la educación en su obra LITERARIA}

Otro de los temas que inquietan e interesan a Juan Castro es todo lo concerniente a la educación y la pedagogía. Estudió Magisterio, y desde muy joven, a los dieciocho años, ya ocupó su primera plaza como maestra tras aprobar la oposición pertinente. Más tarde se especializó en Educación Infantil. Como apunta Joaquín Criado Costa «se traslada a Córdoba en 1974, donde desde entonces vive y ejerce como profesora de preescolar, habiendo sido durante unos años responsable de otras tareas administrativas como la coeducación y el lenguaje igualitario» ${ }^{33}$. Conocedores de su

\footnotetext{
${ }_{30}$ Persin, M., «Mujer y ciudadanía [...]», art. cit., p. 129.

${ }^{31}$ Se denomina 'halcón niego' a aquel cogido en el nido o recién salido de él.

${ }^{32}$ Porro Herrera, M. J., «Semblanza crítica», en Portal de Juana Castro del Centro Virtual Cervantes, 2006. Disponible en: http://www.cervantesvirtual.com/portales/juana_castro/semblanza/ [consultado 1701-2017].

${ }^{33}$ Criado Costa, J., Poesía de granito y jara: Juana Castro, art. cit., p. 204.
} 
interés y experiencia en las cuestiones de didáctica, preguntamos a la autora qué podría hacerse, en su opinión, para estimular a los niños y jóvenes a entrar en la poesía. Su respuesta fue la siguiente:

La poesía sería la primera oración / invocación de la jornada, es importante la oralidad, volver a las trovas o a la juglaría. Un poema para cada día, una autor o autora a la semana, cuatro autores al mes... por nueve meses se pueden dar treinta y seis poetas.

Un cuaderno, Mi Cuaderno de Poesía -no de poesías, que hay mucha gente que confunde el género con la pieza-. Recopilar los poemas y poetas que le gusten a cada cual, pero oral y materialmente: leídos, dramatizados, memorizados, escritos...

Segunda fase: escribir un poema al modo, temática o versificación de... De ahí a la propia escritura se pasa cantando. Si se desea, claro.

Si en cada centro escolar, desde los 3-4 años se dedicara media hora diaria a la poesía, se haría a la vez educación en valores, educación sentimental, potenciaríamos la inteligencia emocional... Emocionarse por la palabra es la mejor clase de ética ${ }^{34}$.

Se muestra la poeta muy consciente de la necesidad de la enseñanza de la poesía desde edades tempranas, siempre y cuando se haga de un modo riguroso y alejado de la repetitiva y monótona praxis habitual. Su obra supone también, en parte, una defensa encendida de la educación poética, como medio de transmisión lingüística, cultural, ética y estética. En esa atmósfera escolar de las aulas, tan conocida por Juana Castro, ambienta la autora el poema «Fin de curso», perteneciente a su libro La jaula de los mil pájaros ${ }^{35}$.

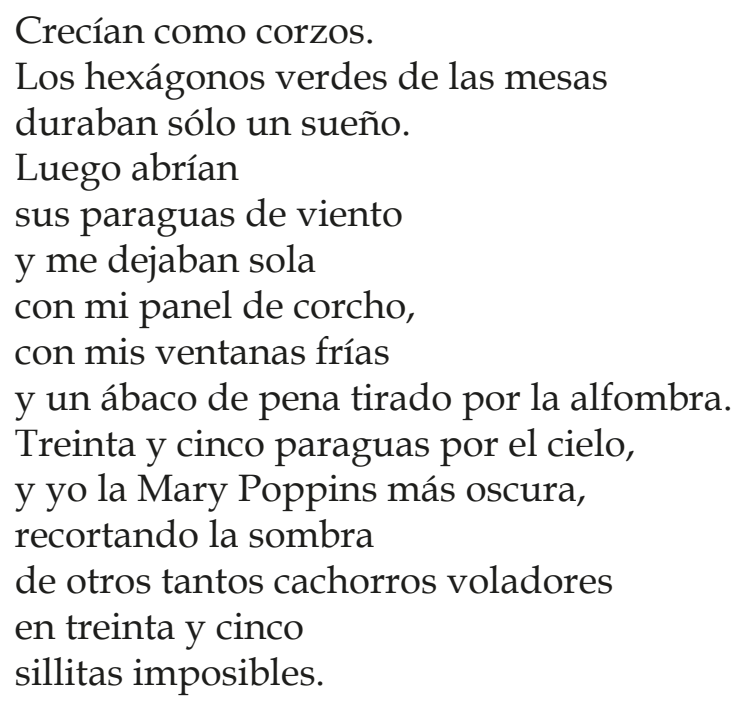

La melancolía de la maestra, al quedarse sola en el aula, tras el extenuante

\footnotetext{
${ }^{34}$ Entrevista personal a Juana Castro, realizada en Córdoba a 26 de febrero de 2016. Contenida en Los poetas toman la palabra [...], ob. cit. s/p.

${ }^{35}$ Castro, J., La jaula de los mil pájaros, Málaga, Rafael Inglada, 2004.
} 
La construcción identitaria en la poesía de Juana Castro. Compromiso e indagación, claves para una educación...

trabajo de un curso escolar, se refleja de modo muy plástico en el poema. Sin ornatos ni aliños, la poeta lanza el mensaje preciso, esa suerte de labor de Sísifo que cada año -con alumnos que siempre tienen la misma edad mientras ella va envejeciendo- se ve obligada a recomenzar una y otra vez.

\section{Conclusiones. El compromiso y la equidad como leitmotiv para la educación LITERARIA.}

Para Juana Castro, según María José Porro Herrera, «toda poesía hay que entenderla como «un medio de conocimiento de mí misma y del mundo que me rodea ${ }^{36}$. De todas formas, en nuestra opinión, no hay poeta sin maestros, y sabedores de las múltiples admiraciones poéticas que ha cultivado Juana Castro, muchas de las cuales traslucen en su poesía, le hemos preguntado por los más importantes de entre los suyos. Su respuesta es especialmente significativa:

Ese fue el primer conflicto. Yo, sabiéndome mujer, quería maestras, y apenas contaban más que las monjas, el canon que conocí no visibilizaba a las mujeres, tuve que buscarlas yo. Y eso lleva su tiempo. Juana de Ibarbourou, Gabriela Mistral, Alfonsina Storni, Rosalía de Castro. Pensadoras como María Zambrano, Simone Weil, Helene Cixous, Hannah Arendt, Luce Irigaray. Ideólogas como Milagros Rivera Garretas. Poetas como Adrienne Rich, Safo, Ernestina de Champourcin, Sor Juana, Emily Dickinson, María Beneyto, Ángela Figuera, Sharon Olds, Gloria Fuertes, Szymborska, Concha Lagos, Marosa di Giorgio, Julia Uceda, Ana $\mathrm{M}^{\mathrm{a}}$ Moix, Carmen Conde, Clarice Lispector, Adelaida García Morales, Yoko Ogawa... Y algunos hombres como García Lorca, José Hierro, Rafael Pérez Estrada, Pablo García Baena, Gabriel García Márquez, Góngora...Y Cervantes ${ }^{37}$.

Este tema de la ausencia o poca presencia de mujeres en el canon literario nos parece esencial para poder lograr una equidad de géneros -o al menos de las oportunidades que disfrutan ambos géneros- también en el ámbito del arte. Juana Castro ha demostrado que para ella la poesía puede ser, también, un modo de luchar contra las injusticias y de visibilizar las desigualdades para ayudar a paliarlas. Solamente conociendo el dolor se puede ayudar a menguar el dolor, solamente se puede soñar con volar desde las alas. Juana Castro sabe muy bien esta verdad, como demuestra este poema, «iSeñor! , perteneciente a su libro titulado precisamente Del dolor y las alas ${ }^{38}$, del que reproducimos los últimos versos:

La espalda es una curva que sujeta mi madre y no sé ni llorar, porque el dolor me anega como un grito.

Mis hermanas están frente a la aurora

\footnotetext{
${ }^{36}$ Porro Herrera, M. J., «Semblanza crítica», art. cit.

${ }^{37}$ Entrevista personal a Juana Castro, realizada en Córdoba a 26 de febrero de 2016. Contenida en Los poetas toman la palabra [...], ob. cit. s/p.

${ }^{38}$ Castro, J., Del dolor y las alas, Villanueva de Córdoba: Ayuntamiento de Villanueva de Córdoba, 1982.
} 


$$
\begin{aligned}
& \text { con un panal abierto en las rodillas. } \\
& \text { Yo me miro las cuencas maduradas } \\
& \text { y te clamo ¡Señor! porque tu nombre verde } \\
& \text { es el único tallo que sostengo } \\
& \text { desde que el mar me muerde y me vendimia. }
\end{aligned}
$$

La conciencia de la desigualdad de géneros que sufrió desde su juventud, la voluntad firme de eliminarla, la capacidad de empatización con el otro y su constante preocupación por la educación y la pedagogía, hacen de la obra poética de Juana Castro un material idóneo para trabajar la educación literaria y emocional de los lectores. Su voz trascendida, alejada de simplificaciones y slogans, la convierte en un referente de la poesía española contemporánea, así como en una autora imprescindible para ahondar en la búsqueda de la libertad, la lucha contra la alienación y la construcción de la identidad femenina.

\section{BibLIOGRAFÍA}

BALCELlS, J. M, «El mito del origen en la poesía de Juana Castro», Estudios Humanísticos. Filología, 25 (2003), pp. 175-183.

CAstellet, J. M., Nueve novísimos poetas españoles, Barcelona, Barral Editores, 1970.

CAstro, J., Cóncava mujer, Córdoba, Zubia, 1978.

, Del dolor y las alas, Villanueva de Córdoba, Ayuntamiento de Villanueva de Córdoba, 1982.

, Paranoia en otoño, Valdepeñas, Ayuntamiento de Valdepeñas, 1985. , Narcisia, Barcelona, Taifa, 1986.

, Arte de cetrería, Huelva, Diputación de Huelva, 1989.

, Fisterra, Madrid, Libertarias-Prodhufi, 1991.

, No temerás, Madrid, Torremozas, 1994.

, Memoria della luce, Bari, Levante Editori, 1996.

, Del color de los ríos, Ferrol, Esquío, 2000a.

, El extranjero, Madrid, Rialp. Col. Adonái, 2000b.

, La jaula de los mil pájaros, Málaga, Rafael Inglada, 2004.

, Los cuerpos oscuros, Madrid, Hiperión, 2005.

, La Bámbola. Intrusos en la red, Jerez, EH Editores, 2010.

- Cartas de enero, en Heredad seguido de Cartas de enero, Sevilla, Fundación José Manuel Lara, 2010.

Coco, E., La poesía de Juana Castro, Córdoba, Francisco Gálvez D.L., 1992.

CRIADO COSTA, J., «Evolución poética de Juana Castro», Boletín del Instituto de Estudios Giennenses, 153, 1 (1994), pp. 159-179. 
La construcción identitaria en la poesía de Juana Castro. Compromiso e indagación, claves para una educación...

, «Poesía de granito y jara: Juana Castro», en Boletín de la Real Academia de Córdoba de Ciencias, Bellas Letras y Nobles Artes, 135 (1998), pp. 203-216.

EnRIQue, A., «Poética» en web personal del escritor Antonio Enrique, 2009. Disponible en: http://www.antonioenrique.com/Poetica\%202009.html [consultado 18-022016].

García Martín, J. L., La generación de los ochenta, Valencia, Mestral, 1988.

García Posada, M., La nueva poesía española (1975-1992), Barcelona, Crítica, 1996.

Gil de BiezMA, J., El pie de la letra, Barcelona, Mondadori, 2001.

LANSEROS, R., Los poetas toman la palabra. La construcción de la educación literaria en los autores nacidos en posguerra, Madrid, Visor Libros, 2017.

MartíneZ, J. E., «Experiencia y experimentación (res/verba) en la poesía española última», Estudios humanísticos. Filología, 20 (1998), pp. 211-224.

MéKouAR-HertzberG, N., «Escritura del "yo" imposible», Revista de estudios de ciencias sociales y de humanidades, 33 (2015), pp. 23-29.

Morales Lomas, F., Poesía viva. Ensayos sobre poesía española, Málaga, Fundación Unicaja, 2013.

NúÑEz RuIz, G., Lectura literaria y lecturas del mundo: Notas sobre la lectura y la educación literaria, Almería, Universidad de Almería. Red de Universidades Lectoras, 2014.

Peñas-Bermejo, F. J., «La poesía de Juana Castro: “¿Destino de la luz no fuera el encenderse?"», Salina: revista de lletres, 16 (2002), pp. 213-218.

Persin, M., «Mujer y ciudadanía: los casos de Concha Zardoya y Juana Castro», Lectora: revista de dones i textualitat, 15 (2009. Número dedicado a: Mujeres y naciones), pp. 117-134.

Porro Herrera, M. J., «Semblanza crítica», en Portal de Juana Castro del Centro Virtual Cervantes, 2006. Diponible en: http://www.cervantesvirtual.com/ portales/juana_castro/semblanza/ [consultado 17-01-2017].

Rodríguez, J. C., Dichos y escritos (Sobre «La otra sentimientalidad» y otros textos fechados de poética), Madrid, Hiperión, 1999.

Rodríguez JiméneZ, A., «La creación poética en Cuadernos del Sur, emblema literario de estética y compromiso», en SÁNCHEZ GARCíA, R., Palabra heredada en el tiempo. Tendencias y estéticas en la poesía española contemporánea (1980-2016), Madrid, Akal, 2016, pp.135- 147.

SÁnchez García, R., El canon abierto (Última poesía en español), Madrid, Visor, 2015.

UGALDE, S. K., «Introducción: la aventura del sujeto lírico femenino en la poesía de Juana Castro», en Ugalde, S. K. (ed.), Sujeto femenino y palabrapoética: Estudios críticos de la poesía de Juana Castro, Córdoba, Diputación de Córdoba, 2002, pp. 12-21.

VillenA, L. A. DE, Postnovísimos. Madrid: Visor, 1986. 